Article

\title{
Consumers' Perceptions of Sustainable Wine: An Exploratory Study in France and Italy
}

\author{
Roberta Capitello ${ }^{1, *(\mathbb{D})}$ and Lucie Sirieix ${ }^{2}$ (D) \\ 1 Department of Business Administration, University of Verona, 37129 Verona, Italy \\ 2 UMR MOISA, Montpellier SupAgro, CIHEAM-IAMM, CIRAD, INRA, Univ Montpellier, 2 Place Viala, 34060 \\ Montpellier, France; lucie.sirieix@supagro.fr \\ * Correspondence: roberta.capitello@univr.it
}

Received: 30 October 2018; Accepted: 5 February 2019; Published: 25 April 2019

\begin{abstract}
This study offers new insights into the sustainable wine market by exploring consumers' perceptions of product attributes for six categories of wine that have characteristics of sustainability and one conventional wine. The study investigates product-attribute associations that French and Italian consumers attach to sustainable wines, and whether consumers' involvement with wine and propensity towards ethically-minded behaviours affect their perceptions of sustainable wines. The research employs a cross-country analysis of France and Italy, and uses a free-choice approach to reveal consumers' perceptions. The perceptual maps highlight the different attribute dimensions associated with conventional wines and sustainable wines. Health benefits, taste, and ethics emerge as the most relevant discriminant dimensions. The study finds that consumers involved with wine demonstrate a greater ability to evaluate product-attribute associations for sustainable wines than do ethically-minded consumers who are not involved with wine. The study elaborates some practical implications of this result for wineries. In particular, the study highlights that consumers associate different characteristics and beneficial aspects with different categories of sustainable wines; this also depends on their level of involvement with wine. The results demonstrate that sustainable wine marketers should, in their marketing and communication, take into stronger consideration the level of consumer involvement with wine and the specific associations made by consumers with the sustainable wine category they want to promote.
\end{abstract}

Keywords: sustainable wine; wine-consumer perceptions; ethically-minded consumer behaviour; wine involvement; pick-any approach

JEL Classification: Q01; Q18; M31; D12

\section{Introduction}

Today, sustainability is one of the most relevant factors in transforming food-production strategies and food-consumption behaviours. It is a challenge for agrofood systems to innovate and make changes in agricultural practices, food processing, business governance and relationships with the market (Adams et al. 2016). However, agrofood businesses pursue sustainability as an opportunity to offer new value propositions to customers and improve their competitive advantage (Reisch et al. 2013).

Sustainability is the subject of countless discussions in public debate and policy agendas. The breadth of the concept of sustainability is constantly evolving as awareness about the effects of human behaviour on natural resources and the environment, and the negative effects on environmental equilibria (e.g., pollution and climate change) increases in society. Agenda 2030 (UN 2015) is the most recent attempt to frame the issues of sustainable development within a global vision. The established 17 Sustainable Development Goals (SDGs), 169 targets, and more than 200 indicators demonstrate 
the multifaceted dimensions of sustainability that should be considered in today's public institutions and society. Agrofood systems are directly or indirectly interconnected with the achievement of the SDGs (e.g., good health and wellbeing, affordable and clean energy, decent work and economic growth, sustainable cities and communities, and responsible consumption and production, to name a few) (FAO 2018).

In the marketplace for wine products, the concept of sustainability has multiple nuances for producers that result from the confluence of business motivations, internal or external stimuli, and a business's degree of responsiveness to these (Santini et al. 2013). According to Gilinsky et al. (2016), the approaches of wine businesses to sustainability should incorporate the 'triple-bottom line', including social, environmental, and financial stewardships, in corporate strategy and policy.

A cross-national study conducted in seven wine-producing countries by Szolnoki (2013) revealed different understandings of sustainability in the wine industry even between wine producers located in the same region or country. Spielmann (2017) found diversity in environmental sustainability attitudes and practices in the French wine industry that are causally related to business size and engagement in direct investment in foreign markets.

Baird et al. (2018) found that New Zealand winegrowers faced significant economic, environmental, social, and marketing challenges from the supply-side perspective in response to sustainability. They indicated substantial concerns with the perceived value provided by sustainable winegrowing practices at both the firm and governing-body levels.

The ambiguity of the concept of sustainability and the uncertainty about economic return on investments in sustainability represent a source of concern in the wine industry. Thus, a range of approaches to sustainability are adopted by wine producers: some use sustainable practices as an incentive for innovation and marketing differentiation without having a genuine attitude of ensuring business sustainability; others consider themselves guardians of natural resources and product typicality, but fear that any associated virtuous behaviours are minimally recognised by the market so are reluctant to invest in sustainable practices (De Salvo et al. 2018; Santini et al. 2013; Spielmann 2017).

Recent studies have highlighted that different sustainability certifications have appeared in the past decade in many wine-producing regions (Flores 2018; Martins et al. 2018; Moscovici and Reed 2018). However, the management of sustainability remains underdeveloped in many of the certification frameworks, and the elaboration of new business strategies and policies in line with consumer demand is also lacking (Martins et al. 2018). In a cross-country analysis of several sustainability-assessment frameworks, Flores (2018) confirmed Martins et al.'s (2018) findings. Flores (2018) noted that sustainability frameworks focus on operational issues, while their strategic thinking remains underdeveloped. In addition, according to Moscovici and Reed (2018), there is a need for more research into the consumer perspective of sustainability certifications.

These uncertainties from the supply side are further complicated by consumers' perceptions. The intrinsic multidimensional significance of sustainability and the diversity of products on the market claiming to be sustainable generate different perceptions and motivations for choice by consumers (Schäufele and Hamm 2017).

A country's cultural values and consumer lifestyle can influence sustainable consumption. Minton et al. (2018) found that a nation's level of pragmatism is positively correlated with the sustainable behaviour of individuals, and sustainable attitudes mediate the relationship between national cultural values and consumer behaviour. Thøgersen (2017) noted that both national and individual factors, such as country of residence and food-related lifestyle, interact and significantly affect everyday food choices and sustainable consumption in Europe.

In a literature review, Schäufele and Hamm (2017) observed that previous research highlights the low level of wine consumers' awareness of the concept of sustainability; nevertheless, their study shows that consumers have positive perceptions and are willing to pay a premium for wine with characteristics of sustainability. Consumers generally connect sustainable wines with ecologically-friendly products and production following organic practices (Schäufele and Hamm 2017). In a study conducted by 
Mueller Loose and Remaud (2013), consumers from different countries worldwide evaluated a range of claims about social and environmental responsibility. Claims relating to corporate environmental responsibility, and organic production in particular, were found to have a higher effect on consumer choice and willingness-to-pay than any other sustainability label. Such claims have become an indicator of product quality for consumers (Schäufele and Hamm 2017).

A little-understood aspect of the wine market, which is now characterised by an increasing range of different products claiming sustainability (e.g., organic wines, biodynamic wines, wines preserving biodiversity or reducing carbon emissions), are the conceptual meanings and differences that consumers comparatively ascribe to such wines (Remaud and Sirieix 2012).

Wineries considering investing in sustainability to differentiate their product portfolio should understand consumers' perceptions of different types of wine that are claimed to be sustainable. For these businesses, it would also be of interest to investigate the positioning of these types of products compared with conventional wine, that is, wine that does not make any claims about sustainability or certification.

For sustainable wine, environmental soundness is the most prominent distinctive characteristic, but there are other aspects of sustainability (e.g., fair trade, natural) that deserve more research attention (Schäufele and Hamm 2017). The comparative positioning of different types of sustainable wines (i.e., the attributes that allow for differentiation within the category of sustainable wine) has been largely ignored in the research (Remaud and Sirieix 2012).

Thus, the purpose of this study is to compare consumer perceptions of wines with different characteristics of sustainability (e.g., organic wine, biodynamic wine, fair-trade wine). The practical aim of this study is to provide wine producers focusing on sustainability practices with suggestions about which attributes consumers associate with different sustainable wine categories and how to ensure consistency between a product's attributes of sustainability and consumer perceptions of the product. This knowledge provides winemakers, marketers and public institutions with new insights on how to achieve more effective policy and communication actions for the promotion of sustainable choices. From a theoretical perspective, this study contributes to understanding more responsible practices in production systems-one of the principal challenges in contemporary agriculture and in the transformation of competitiveness of agrofood businesses-from the perspective of a demand analysis.

\section{Background and Research Questions}

There is an extensive body of literature on sustainable-food and organic-food consumption (Aertsens et al. 2009; Reisch et al. 2013; Thøgersen 2017; Vermeir and Verbeke 2006). However, research is still needed on the relationship between sustainability concerns and sustainable-product preferences to provide new insights into policy and communication efforts that can successfully promote sustainable choices.

In the wine sector, several recent studies have shown that consumers are generally interested in wines produced in an environmentally friendly or socially responsible manner (Ginon et al. 2014; Pomarici and Vecchio 2014; Remaud and Sirieix 2012; Schäufele and Hamm 2018). However, compared with other industries, consumers hold the perception that the wine industry is already 'green', and this creates one of the biggest barriers to the success of the sustainable wine sector (De Salvo et al. 2018; Sogari et al. 2016). Wine is generally perceived to be a 'natural' product; thus, unlike for other 'natural' food products, claims of wine being organic have failed to create an important element of differentiation (Remaud and Sirieix 2012; Sogari et al. 2016).

However, this situation is changing, as evidenced by more conscious and informed consumers increasingly favouring wines that are produced through natural processes and free from chemicals (Schäufele and Hamm 2017).

According to Shine (2018), the wine and spirits consultancy organisation IWSR has estimated that the market for organic wine (the product category most closely associated with sustainable wine in Europe) will grow rapidly in the next five years, even if the share of organic wines on the global 
wine market remains relatively low at 3.6\% (compared with $2.4 \%$ in 2017). An IWSR report envisages that global sales of organic still wine will top 1 billion bottles by 2022, up from 676 million 2017 last year and nearly three times the 349 million bottles sold in 2012 (Shine 2018). Growth in the five-year period from 2017 to 2022 will be driven by the United States, which is predicted to have a more than $14 \%$ increase. Nearly four bottles out of every five of organic wine sold in 2017 were in Europe, with three leaders in these sales: Germany (162 million bottles; 23.9\% of world market), France (111.6 million bottles; 16.4\%), and the United Kingdom (68.4 million bottles; 10.2\%) (LSA 2018). In France, the increase in organic wine sales is particularly strong, and the market share is predicted to reach $7.7 \%$ by 2022 (LSA 2018). In Italy, only 15.6 million bottles were sold ( $2.3 \%$ of the world market) in 2017 (Shine 2018). The organic-wine market in Italy remains a niche market, but the predictions are very positive. According to Sinab (2018), while the global value of wine sales in supermarkets in Italy increased by $4.5 \%$ in the first semester 2018 (compared with the first semester 2017), organic wine sales increased by $49.3 \%$ in the same period.

The sustainable-wine market is developing from being a niche market towards being a market segment with growth potential and product differentiation (e.g., biodynamic wine, natural wine or fair-trade wine; CBI 2016). However, consumer involvement with the quality of sustainable products and efforts in sustainable-production practices remain a challenge for the wine industry. According to Sogari et al. (2015), involvement with wine and environmental consciousness are important factors in engaging consumers with sustainable winegrowing. Therefore, this study analyses whether, and how, these factors interact with consumer perceptions of wines that have different characteristics of sustainability.

\subsection{Consumers' Concern for Sustainability and Sustainable Wines}

Consumers have become more health and environmentally conscious (e.g., Klöckner 2013; Thøgersen 2011) and more concerned about from where their food comes (Dowd and Burke 2013). However, consumers' general concern about sustainability is not well reflected in their actual behaviour, and sustainability labels do not currently play a major role in consumers' food choices (Grunert et al. 2014).

Wine is essentially an agricultural product; thus, sustainability plays a very significant role in the wine business. One of the many problems that the wine industry must address is the environmental consequence of making wine (Szolnoki 2013). Today, rising energy prices, water scarcity, concerns about chemical exposure, and climate change threaten the wine industry (Gilinsky et al. 2016).

Consumers, winemakers, and wine companies remain confused about the meaning of terms such as 'sustainable winemaking'. Sustainable grape growing and winemaking constitute a much broader concept than organic, biodynamic or integrated pest/crop management (Szolnoki 2013; CBI 2016).

Indeed, the results of a study conducted in Canada (Rojas-Méndez et al. 2015) did not suggest that people who are highly concerned about the environment were more likely to have positive attitudes towards organic wine.

A study conducted by Ginon et al. (2014) evaluated French consumers' perception of logos that indicate environmentally sustainable production. The research used 14 logos currently used in France: three that are specifically related to wine production and 11 that refer more generally to sustainable practices. The research concluded that the numerous logos claiming environmental sustainability are confusing for consumers, which may be partially responsible for a reduction in the credibility of some logos. Consequently, the research suggested that consumers should be provided with better information about environmental sustainability and researchers should further investigate the topic. The research also observed that consumers lack knowledge about logos that indicate environmental sustainability. None of the logos relating to sustainable-wine practices was known to the consumers (Ginon et al. 2014). This observation may indicate that the large number of logos currently on the market is confusing and reduces credibility. This has become a major issue for the wine industry (Sogari et al. 2016). 


\subsection{Consumer Involvement with Wine}

Many studies have linked product involvement to wine-purchasing behaviours. Consumers with different levels of involvement behave differently (Yuan et al. 2008). Patterns of wine purchase are also affected by consumers' involvement with wine (Bruwer and Huang 2012; Lockshin and Spawton 2001). Barber et al. (2008) found that wine buyers with high and low levels of involvement have different reactions to price-per-bottle, country or region of origin, grape variety, and label design. Highly-involved consumers tend to use complex information cues when choosing a wine, and generally buy larger quantities of wine and spend more per bottle (Barber et al. 2008).

Previous studies have reported contradictory results on the relationship between involvement with wine and organic-wine consumption. According to Mann et al. (2012), consumers who think of themselves as wine lovers usually prefer organic wine. Conversely, Rojas-Méndez et al. (2015) found that the attitude towards organic wine is positively influenced by consumers' health consciousness and negatively influenced by a higher level of wine-involvement pleasure. Hedonism explains the consumption of wine in general, as well as why organic wine is not consumed more by consumers involved with wine, that is, these consumers do not associate organic wine with a good taste or a pleasant past experience and so, will not choose to buy such wine (Rojas-Méndez et al. 2015). More generally, it has been found that consumers do not associate wine ecocertification with a good taste (Rojas-Méndez et al. 2015).

Although involvement with wine has been largely investigated in studies of wine consumers, only several of these studies (Sogari et al. 2015, 2016) have segmented consumer perceptions of sustainable wines with levels of consumer involvement with wine.

\subsection{Ethical and Environmental Consciousness}

Extensive research has been conducted analysing consumers' attitudes towards ecological and ethical behaviours and the issue of the attitude-behaviour gap (Sudbury-Riley and Kohlbacher 2016). Sogari et al. (2016) found that valuing environmental protection does not affect the importance of sustainability during wine purchases; however, the belief that sustainable products provide benefits to the environment influences consumers' attitudes towards wine. Corporate social responsibility is positively evaluated by wine consumers (Mueller Loose and Remaud 2013). However, consideration by consumers of the ecofriendly characteristics of sustainable wine is relevant, which is not the case for ethical considerations. Ethical characteristics are relevant for a niche of wine consumers, but ethical products and fair-trade marketing initiatives are attracting an increasing number of consumers (Sudbury-Riley and Kohlbacher 2016). The contemporary concept of sustainability encompasses environmental and ethical considerations, and social issues such as recycling, waste reduction, resource saving, social justice, and human rights, are becoming motivations that are driving choice or boycott for many consumers (Carrington et al. 2014; Sudbury-Riley and Kohlbacher 2016).

Therefore, this study uses the measurement scale proposed by Sudbury-Riley and Kohlbacher (2016) because it enables the measurement of consumers' sensitivity to environmental concerns, as well as the ethical implications of the wine business.

\subsection{Research Objectives and Questions}

This study seeks to offer new insights into the sustainable-wine market by exploring consumers' perceptions of sustainable wines. Specifically, this study aims to investigate whether wine involvement and a propensity towards ecologically and ethically-minded behaviours affect consumers' perceptions.

First, it explores consumers' perceptions of sustainable wine and product attributes associated with several categories of sustainable wine. It investigates the relationship between consumers' concerns about sustainability, their wine involvement and the product attributes they associate with sustainable wine. 
The study adopts a cross-country analysis, comparing results from France and Italy. These countries have in common a long tradition of wine consumption and production. In addition, French and Italian consumers in general show high involvement with wine. In both countries, the preferences of wine consumers are mainly driven by proximity to wine-producing areas and the wine producers; geographical indications (i.e., Protected Designations of Origin and Protected Geographical Indications) play a relevant role in wine-consumer choices (e.g., Casini et al. 2009). Sustainable consciousness has only recently begun to increase among wine producers and consumers (Flores 2018; Moscovici and Reed 2018). Therefore, it is interesting to analyse whether similar trends of perceptions can be found in the two countries.

The cross-country analysis seeks to answer the following research questions:

1. Which product-attribute associations do French and Italian consumers attach to sustainable wines? What are the perceived differences of such wines compared with conventional wines?

2. Which associations are country specific, and which are product specific?

3. How does wine involvement affect consumers' perceptions of sustainable wine?

4. How does a propensity towards ecologically and ethically minded behaviour affect consumers' perceptions of sustainable wine?

\section{Methodology}

To answer the research questions, a quantitative survey by questionnaire was conducted in France and in Italy.

The questionnaire aimed to capture consumers' perceptions of wines with different characteristics of sustainability and their attitudes towards wine and sustainability.

The questionnaire had three parts. The first part was used to involve respondents in the questionnaire and the topic of sustainability by asking them about their general awareness and their immediate perceptions of sustainable wine through open-ended questions.

The second part was designed to answer specifically the research questions of this study. It used a free-choice approach and the 'pick-any' technique (Driesener and Romaniuk 2006). The pick-any technique allowed us to explore which product attributes consumers associated with conventional wine and sustainable wine. Specifically, respondents were asked to state which attribute(s) they associated with each proposed category of wine. They could freely link any, all or no wine to each attribute.

The list of attributes was adapted from an earlier study by Remaud and Sirieix (2012) conducted in Australia and France. This list was revised according to the most recent literature in the field (Moscovici and Reed 2018; Sirieix et al. 2013). The list was also confirmed for the Italian sample through the positive results of a test we conducted through a focus group in Italy among a group of master students. In the questionnaire, attributes were presented to the respondents in random order. The list of attributes consisted of 18 items representing the following four groups of wine characteristics (Table 1):

- five concrete characteristics (i.e., good value for money; more expensive; low quality; genuine taste; distinctive taste)

- $\quad$ five image characteristics (i.e., traditional; luxurious; innovative; linked to its origin; requiring education to appreciate)

- four benefits to the consumer (i.e., does not cause headaches; good for health; pleasurable and fun; trendy)

- four benefits to society (i.e., harmless to the environment; a more responsible winemaker; supports local production; respect for ethical values).

The list of wines was also adapted from an earlier study by Remaud and Sirieix (2012) conducted in Australia and France, and revised according to Sirieix et al. (2013) findings and the most recent literature in the field (Flores 2018; Mueller Loose and Remaud 2013; Moscovici and Reed 2018). The list 
of wines contained the following six wines defined as sustainable and accessible to consumers in both Italy and France (CBI 2016; Mariani and Vastola 2015):

- organic wine (i.e., a wine certified according to the European Union's regulations and standards, and produced without the use of any artificial chemicals in accordance with organic-viticulture principles and organic-winemaking techniques)

- biodynamic wine (i.e., a wine certified in accordance with Demeter International standards; winegrowing follows organic farming principles and is based on respecting living ecosystems and their natural equilibria)

- wine with no added sulphites (i.e., a wine produced without adding sulphites during the wine-making process)

- natural or sustainable-development wine promoted by producers' organisations, for example, VinNatur (an association of natural wine producers) or the VIVA project (the Evaluation of the Impact of Viti-viniculture on the Environment) in Italy, or Vignerons en Développement Durable (VDD) in France (i.e., a wine following a voluntary private or public protocol and certification shared by a group of producers and promoting sustainable wines based on their naturalness or the producer's social responsibility)

- fair-trade wine (i.e., a wine certified by Fairtrade International or Fair for Life, which signals a wine produced following principles of respect for economic and social as well as environmental standards)

- carbon-neutral wine (i.e., a wine claiming the reduction of carbon emissions or undertaking actions to compensate carbon emissions).

The list also included conventional wine so that the respondents could also consider a wine product that had no sustainability features.

Table 1. Attributes used to elicit consumers' perceptions through the pick-any technique.

\begin{tabular}{cccc}
\hline Concrete Characteristics & Image Characteristics & Benefits to the Consumer & Benefits to Society \\
\hline \#6 Low quality & $\begin{array}{c}\text { \#7 Requiring education } \\
\text { to appreciate }\end{array}$ & \#3 Does not cause headaches & \#1 More responsible winemaker \\
\hline \#12 Genuine taste & \#9 Traditional & \#4 Pleasurable and fun & \#2 Harmless to the environment \\
\hline \#13 More expensive & \#10 Luxurious & \#5 Trendy & \#15 Supports local production \\
\hline \#14 Good value for money & \#11 Innovative & \#8 Good for health & \#17 Respect for ethical values \\
\hline \#18 Distinctive taste & \#16 Linked to its origin & & \\
\hline
\end{tabular}

The third part of the questionnaire was designed to collect information about consumers' concerns relating to sustainability and their ethically minded behaviour, wine involvement and sociodemographic characteristics. We used the ethically minded consumer behaviour (EMCB) scale developed by Sudbury-Riley and Kohlbacher (2016) to explore respondents' attitudes towards the concept of sustainability. Respondents' involvement with wine was evaluated using a scale proposed by Yuan et al. (2008).

The questionnaire was elaborated in English and then translated into French and Italian by the authors and subsequently back-translated into English by two master's students who speak the three languages fluently. Data were collected through an online consumer survey. Following previous studies (Sogari et al. 2015, 2016), the questionnaire was sent by email and posted on social networks in France and Italy, between June and October 2016. The questionnaire was advertised through a convenience sample of Facebook pages among groups of wine connoisseurs and, more generally, food and wine enthusiasts. This channel was chosen because it reaches consumers who are more likely to know about sustainable wines.

Incomplete questionnaires were eliminated for both surveys. The valid samples consisted of 148 people in France and 210 people in Italy. 
Unsurprisingly, as it was an online survey, the respondents in both samples were mostly young (59\% and $68 \%$ of respondents in the French and Italian samples, respectively, were 40 years of age or younger) and well educated (73\% of French respondents and $69 \%$ of Italian respondents had a university degree). However, the French sample mainly consisted of women $(63 \%)$ and students $(50 \%)$ with low incomes (monthly household income up to 2000 euros in $59 \%$ of cases), whereas most of the Italian respondents were male (54\%) and workers (68\%) with a monthly household income between 1001 and 4000 euros in $63 \%$ of cases. Most respondents in both samples indicated they were regular wine drinkers: $86 \%$ and $74 \%$ of respondents stated that they consumed wine at least several times per month in the French and Italian samples, respectively.

The samples cannot be considered representative of the population of French and Italian wine consumers because the samples are based on willingness to participate and are small. Hence, the results cannot be generalised. However, the application of the pick-any approach allowed us to capture the perceptions of the consumers in our sample, and thus expanded our ability to compare the data between the two countries in a more effective way than another qualitative research method would have (e.g., focus groups).

For information analysis, the data were subjected to a correspondence analysis. Product-attribute associations were represented in a perceptual space through two-dimensional maps (Driesener and Romaniuk 2006). Deviations from the expected level of response were computed and represented in tables of deviations. Deviations were computed for each combination of attribute and category of wine by comparing the 'real' number of selections with the 'theoretical' number of selections. The 'theoretical' number of selections was computed multiplying the number of times an attribute had been selected (regardless the category of wine) by the number of times a category of wine had been selected (regardless the attribute), and dividing by the sample size (Remaud and Sirieix 2012).

Median splits on summed scores for the EMCB and wine-involvement scales were used to identify four types of consumers, combining 'low' and 'high' divisions of EMCB and wine involvement for both countries.

\section{Results}

\subsection{Elicitations for Each Category of Wine by Attribute and Country}

The relative frequencies of elicitations collected through the pick-any technique for each category of wine and country, and grouped by type of characteristic, are summarised in Tables 2-5.

Table 2. Elicitation of concrete characteristics by wine category and country $\left(\%, \mathrm{~N}_{\mathrm{FR}}=148 ; \mathrm{N}_{\mathrm{IT}}=210\right)$.

\begin{tabular}{|c|c|c|c|c|c|c|c|c|c|c|}
\hline \multirow[t]{2}{*}{ Product } & \multicolumn{2}{|c|}{ \#6 Low Quality } & \multicolumn{2}{|c|}{$\begin{array}{l}\text { \#12 Genuine } \\
\text { Taste }\end{array}$} & \multicolumn{2}{|c|}{$\begin{array}{l}\text { \#13 More } \\
\text { Expensive }\end{array}$} & \multicolumn{2}{|c|}{$\begin{array}{l}\text { \#14 Good Value } \\
\text { for Money }\end{array}$} & \multicolumn{2}{|c|}{$\begin{array}{c}\text { \#18 Distinctive } \\
\text { Taste }\end{array}$} \\
\hline & FR & IT & FR & IT & FR & IT & FR & IT & FR & IT \\
\hline 1. Conventional wine & 18.6 & 29.1 & 42.6 & 23.3 & 4.1 & 11.9 & 60.1 & 46.7 & 14.2 & 25.2 \\
\hline 2. Organic wine & 53.3 & 7.4 & 41.9 & 42.4 & 52.0 & 48.1 & 27.0 & 20.0 & 26.4 & 25.7 \\
\hline 3. Biodynamic wine & 35.7 & 10.1 & 34.5 & 22.4 & 52.0 & 44.8 & 12.2 & 8.1 & 31.8 & 25.2 \\
\hline 4. Wine with no added sulphites & 20.0 & 16.9 & 29.7 & 30.0 & 31.1 & 16.7 & 14.9 & 11.4 & 45.3 & 26.7 \\
\hline 5. Natural/sustainable-development wine & 14.8 & 4.7 & 25.0 & 18.1 & 29.1 & 17.1 & 11.5 & 18.6 & 12.2 & 15.7 \\
\hline 6. Fair-trade wine & 15.7 & 10.1 & 18.2 & 10.5 & 37.8 & 11.9 & 10.8 & 22.9 & 12.8 & 9.0 \\
\hline 7. Carbon-neutral wine & 19.0 & 12.2 & 12.8 & 11.4 & 27.7 & 20.0 & 6.8 & 11.4 & 13.5 & 11.0 \\
\hline
\end{tabular}

Note: FR = France; IT = Italy.

Respondents mainly ascribed concrete wine characteristics to conventional wine, organic wine and biodynamic wine (Table 2). Sensory characteristics of wine (i.e., 'Low quality', 'Genuine taste', and 'Distinctive taste') were mainly attributed to conventional, organic and biodynamic wines. Natural/sustainable-development wine was the wine least associated with low quality. French and Italian respondents had different opinions concerning the attributes of quality between conventional and organic wine; however, they agreed on the association of genuine taste with organic and natural/sustainable-development wines and wines with no added sulphites. French respondents reported a distinctive taste for natural/sustainable-development wine and wine with no added 
sulphites. Both samples agreed that organic and biodynamic wine were expensive, and conventional wine provided good value for money. French respondents also considered fair trade and carbon-neutral wines expensive.

The elicitation of image characteristics highlighted interesting consumer perceptions in relation to product-attribute associations (Table 3). Indeed, the attribute 'traditional' was mostly reserved for conventional wine, while biodynamic and carbon-neutral wine were perceived as 'innovative' products. Biodynamic wine emerged as a product that requires more consumer knowledge than the other wine categories. The attributes of 'luxurious' and 'linked to its origin' were not specifically associated with any of the wines.

Table 3. Elicitation of image characteristics by wine category and country $\left(\%, \mathrm{~N}_{\mathrm{FR}}=148 ; \mathrm{N}_{\mathrm{IT}}=210\right)$.

\begin{tabular}{|c|c|c|c|c|c|c|c|c|c|c|}
\hline \multirow[b]{2}{*}{ Product } & \multicolumn{2}{|c|}{$\begin{array}{l}\text { \#7 Requiring Education } \\
\text { to Appreciate }\end{array}$} & \multicolumn{2}{|c|}{ \#9 Traditional } & \multicolumn{2}{|c|}{ \#10 Luxurious } & \multicolumn{2}{|c|}{ \#11 Innovative } & \multicolumn{2}{|c|}{$\begin{array}{l}\text { \#16 Linked to Its } \\
\text { Origin }\end{array}$} \\
\hline & FR & IT & FR & IT & FR & IT & FR & IT & FR & IT \\
\hline 1. Conventional wine & 37.2 & 22.4 & 60.8 & 70.5 & 31.1 & 27.6 & 4.1 & 6.2 & 36.5 & 33.3 \\
\hline 3. Biodynamic wine & 48.0 & 51.9 & 19.6 & 6.7 & 29.7 & 34.3 & 43.9 & 53.3 & 33.8 & 15.2 \\
\hline 4. Wine with no added sulphites & 38.5 & 29.5 & 10.8 & 9.5 & 14.2 & 16.2 & 23.0 & 18.1 & 18.9 & 10.0 \\
\hline 5. Natural/sustainable-development wine & 31.8 & 28.1 & 13.5 & 9.5 & 13.5 & 16.7 & 29.1 & 15.7 & 32.4 & 28.6 \\
\hline
\end{tabular}

Note: FR = France; IT = Italy.

Benefits to the consumer mostly involved conventional, organic, biodynamic and no-added-sulphites wines (Table 4). Health benefits were particularly relevant for wine with no added sulphites and organic wine. The attribute 'pleasurable and fun' was connected with conventional wine; organic and biodynamic wines were instead perceived as trendy products in both countries.

Conversely, benefits to society distinguished natural/sustainable-development, fair-trade and carbon-neutral wines (Table 5). These wines elicited comments about winemakers' responsibility, support for local producers and respect for ethical values. Benefits to the environment were mostly attributed to organic wine for both samples. French respondents also related benefits to the environment to biodynamic wines, and Italian respondents, to carbon-neutral wines.

Table 4. Elicitation of benefits to the consumer by wine category and country $\left(\%, \mathrm{~N}_{\mathrm{FR}}=148 ; \mathrm{N}_{\mathrm{IT}}=210\right)$.

\begin{tabular}{lcccccccc}
\hline & \multicolumn{2}{c}{$\begin{array}{c}\text { \#3 Does Not Cause } \\
\text { Headaches }\end{array}$} & \multicolumn{2}{c}{ \#4 Pleasurable and } & & \multirow{2}{*}{ \#5 Trendy } & & \multirow{2}{*}{ \#8 Good for Health } \\
\hline \multicolumn{1}{c}{ Product } & FR & IT & FR & IT & FR & IT & FR & IT \\
\hline 1. Conventional wine & 12.8 & 9.5 & 64.2 & 40.0 & 4.1 & 18.6 & 23.6 & 6.7 \\
2. Organic wine & 20.3 & 26.2 & 48.0 & 28.1 & 52.7 & 53.3 & 58.8 & 51.4 \\
3. Biodynamic wine & 17.6 & 13.8 & 44.6 & 25.7 & 44.6 & 35.7 & 43.9 & 22.9 \\
4. Wine with no added sulphites & 60.8 & 63.3 & 37.2 & 23.8 & 27.7 & 20.0 & 52.7 & 49.5 \\
5. Natural/sustainable-development wine & 9.5 & 9.5 & 33.1 & 18.1 & 26.4 & 14.8 & 26.4 & 18.1 \\
6. Fair-trade wine & 8.1 & 7.1 & 33.8 & 17.6 & 25.0 & 15.7 & 20.9 & 7.1 \\
7. Carbon-neutral wine & 10.1 & 5.7 & 32.4 & 17.1 & 26.4 & 19.0 & 20.9 & 16.7 \\
\hline & \multicolumn{3}{c}{ Note: FR = France; IT = Italy. } & & &
\end{tabular}

Table 5. Elicitation of benefits to society by wine category and country $\left(\%, N_{F R}=148 ; N_{I T}=210\right)$.

\begin{tabular}{lcccccccc}
\hline & \multicolumn{2}{c}{$\begin{array}{c}\text { \#1 More Responsible } \\
\text { Winemaker }\end{array}$} & \multicolumn{2}{c}{$\begin{array}{c}\text { \#2 Harmless to the } \\
\text { Environment }\end{array}$} & $\begin{array}{c}\text { \#15 Supports Local } \\
\text { Production }\end{array}$ & $\begin{array}{c}\text { \#17 Respect for } \\
\text { Ethical Values }\end{array}$ \\
\hline \multicolumn{1}{c}{ Product } & FR & IT & FR & IT & FR & IT & FR & IT \\
\hline 1. Conventional wine & 4.7 & 14.3 & 3.4 & 4.3 & 18.2 & 22.9 & 6.8 & 5.2 \\
2. Organic wine & 58.1 & 61.0 & 46.6 & 53.3 & 26.4 & 22.4 & 38.5 & 41.0 \\
3. Biodynamic wine & 49.3 & 38.6 & 46.6 & 29.0 & 20.9 & 18.6 & 33.8 & 22.4 \\
4. Wine with no added sulphites & 30.4 & 44.3 & 10.8 & 9.0 & 8.1 & 8.6 & 14.2 & 18.6 \\
5. Natural/sustainable-development wine & 64.9 & 42.9 & 31.1 & 21.4 & 43.9 & 45.2 & 48.6 & 33.8 \\
6. Fair-trade wine & 43.9 & 30.0 & 9.5 & 10.5 & 50.0 & 43.3 & 56.8 & 56.2 \\
7. Carbon-neutral wine & 40.5 & 51.4 & 35.8 & 64.8 & 20.9 & 35.2 & 22.3 & 40.5 \\
\hline
\end{tabular}

Note: FR = France; IT = Italy. 


\subsection{Product-Attribute Associations}

Figures 1 and 2 present consumers' perception maps for product-attribute associations captured by the analysis of the questionnaires for the French and Italian respondents, respectively. The maps demonstrate that there were some similarities between the product-attribute associations of the two samples. However, French respondents appeared to be slightly more able to associate attributes with the proposed products than were Italian respondents. Indeed, in the perceptual map for the Italian sample, some attributes were located near the origin of the dimensions (e.g., pleasurable and fun \#4, luxurious \#10, trendy \#5, and requiring education to appreciate \#7). This means that these attributes tended to be discarded when consumers were asked to characterise some of the proposed wines. In addition, the French respondents were unsure in their evaluations of some attributes (e.g., requiring education to appreciate \#7). In both samples, organic and biodynamic wines were positioned near the origins of axes. This location suggests that perceptions of these categories of wines were different within the groups of informants. Consumers seemed to be uncertain about associating specific attributes to these products. Therefore, they were unable to converge on clear preferences, and a differentiated positioning of these two categories, unlike the others, did not emerge.

Two latent dimensions, Dimension 1 and Dimension 2, explained approximately 80\% of the variance within the French sample and approximately $75 \%$ in the Italian sample. Dimension 1 distinguished the sustainable wines from the conventional wine, and explained $52.1 \%$ of the variance in the French sample and $48.8 \%$ in the Italian sample. Dimension 2 explained $27 \%$ of the variance in both samples and distinguished wine with no added sulphites from other sustainable wines. This dimension was also able to discriminate attributes promoting health and sensory benefits from those linked to the respect of ethics.

The perceptual map of the French consumers (Figure 1) highlights the following:

- conventional wine (Product 1) was mainly perceived as good value for money (\#14) and traditional (\#9)

- wine with no added sulphites (Product 4) was perceived as having a distinctive taste (\#18), not causing headaches (\#3) and being good for health (\#8)

- natural or sustainable-development wine promoted by producers' organisations and fair-trade wine (Products 5 and 6, respectively) were perceived as having the same benefits, that is, respecting ethical values (\#17) and supporting local production (\#15)

- $\quad$ organic wine and biodynamic wine (Products 2 and 3, respectively) were close to the origin of the axes and associated with requiring education to appreciate (\#7), as well as with being trendy (\#5) and expensive (\#13)

- carbon-neutral wine (Product 7) were perceived similarly to organic and biodynamic wines, and were considered expensive (\#5), but respondents recognised this wine as being produced by a more responsible winemaker (\#1) and being harmless to the environment (\#2).

It was evident that some attributes did not have a specific association with any of the proposed wines. The attributes of low quality (\#6), luxurious (\#10), pleasurable and fun (\#4), genuine taste (\#12) and linked to its origin (\#16) were in the positive dimension of the maps, but far from the assessed wines.

The perceptual map of the Italian consumers (Figure 2) highlights the following:

- $\quad$ conventional wine was perceived as being traditional (\#9) and of low quality (\#6), and to a lesser extent as being good value for money (\#14)

- consumers identified wine with no added sulphites as different from the other sustainable wines, perceiving it as not causing headaches (\#3) and being good for health (\#8)

- carbon-neutral wine, natural or sustainable-development wine promoted by producers' organisations and fair-trade wine were located on the opposite side of Dimension 2, far from wine with no added sulphites 
- carbon-neutral wine was perceived as being harmless to the environment (\#2) and respectful of ethical values (\#17)

- organic wine and biodynamic wine were close to each other and shared the characteristics of requiring education to appreciate (\#7) and being trendy (\#5), expensive (\#13) and innovative products (\#11) from responsible producers (\#1).

For the Italian sample, sustainable wine promoted by producers' organisations did not receive any particular attribute association. In addition, some attributes did not receive a specific wine association. This was the case for the characteristics of pleasurable and fun (\#4), luxurious (\#10), genuine taste (\#12), and distinctive taste (\#18).

The analysis of deviations from the expected responses in the French (Table 6) and the Italian (Table 7) samples shows that respondents positively associated conventional wine with the characteristics of tradition, good value for money, pleasurable and fun. Conventional wine is a broad product concept and respondents associated with it the attributes of being low quality and luxurious. However, conventional wine was not seen as trendy, innovative, or more expensive. Respondents also had negative perceptions of the societal benefits of a more responsible winemaker, harmlessness to the environment, and respect for ethical values in the case of conventional wine.

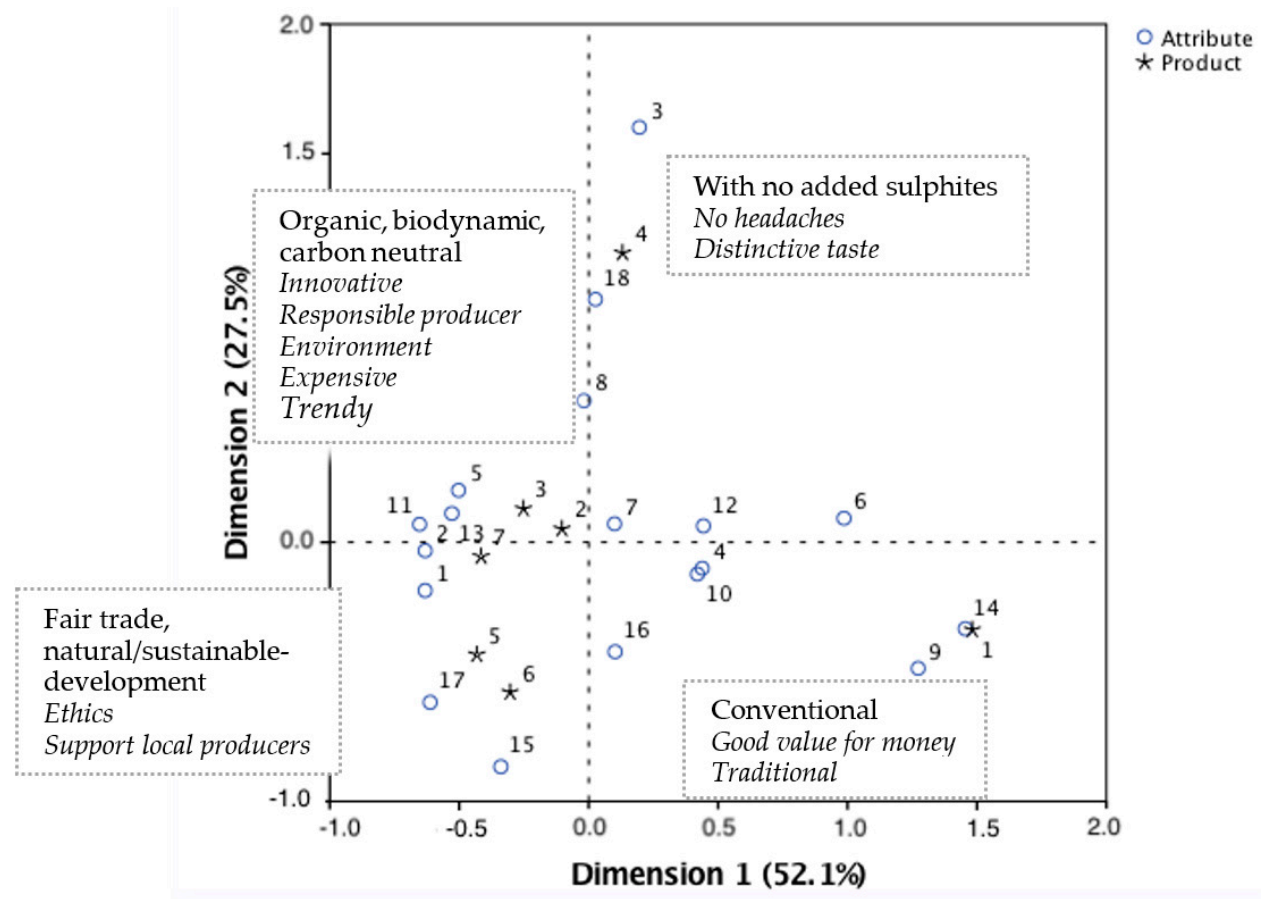

Figure 1. Perceptual map of French consumers' responses $(N=148)^{1}$.

Organic and biodynamic wines received moderate attribute associations in relation to the expected levels of response, as confirmed by their positions for both products and countries close to the centre of the perceptual maps. Organic wine was associated with the characteristics of being harmless to the environment, trendy, good for health and more expensive. For Italian respondents, organic wine also has a genuine taste. Organic wine was not seen as being low quality, traditional, or supporting local production for the Italian respondents. For the French respondents, organic wine was not perceived as having the attributes of being innovative or requiring education to appreciate.

1 Products: 1 = conventional wine; 2 = organic wine; 3 = biodynamic wine; 4 = wine with no added sulphites; $5=$ natural/sustainable-development wine promoted by producers' organisations; $6=$ fair-trade wine; $7=$ carbon-neutral wine. The numbering of attributes is presented in Table 1. 
Biodynamic wine was perceived by both samples as more expensive and innovative, but not able to support local production and not providing good value for money. French respondents highlighted the perception that it can be harmless to the environment. Italian respondents positively associated it with luxury and requiring education to appreciate, but negatively associated it with tradition, respect of ethical values, and links to the origin.

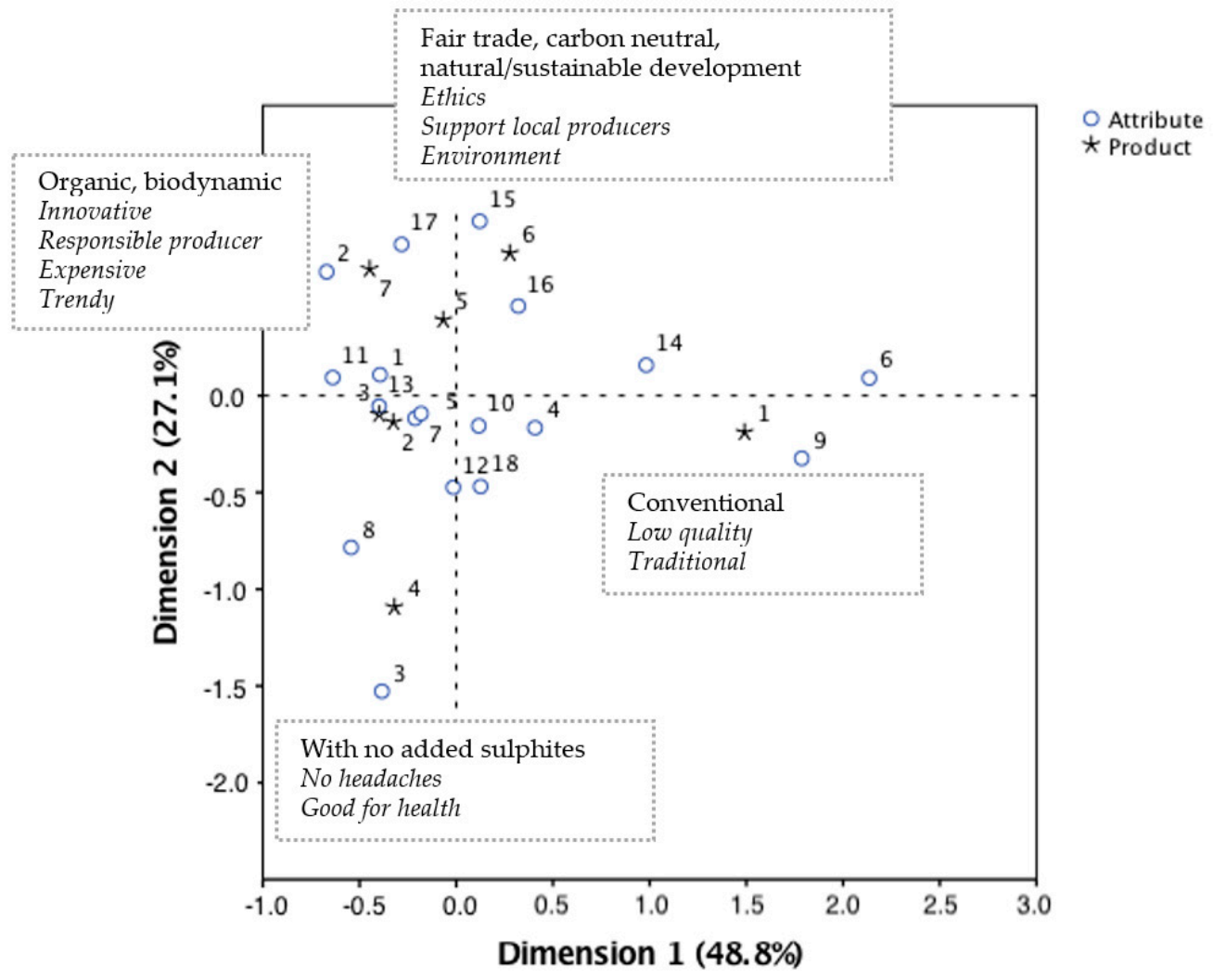

Figure 2. Perceptual map of Italian consumers' responses $(N=210)$.

Table 6. Deviations from the expected levels of responses in the French sample (\%).

\begin{tabular}{|c|c|c|c|c|c|c|c|}
\hline & & & & Wine & & & \\
\hline Attribute & 1 & 2 & 3 & 4 & 5 & 6 & 7 \\
\hline More responsible winemaker & -32.9 & & & & 24.9 & & \\
\hline Harmless to the environment & -20.3 & 13.9 & 14.7 & -14.3 & & -14.4 & 14.5 \\
\hline Does not cause headaches & & & & 41.8 & & & \\
\hline Pleasurable and fun & 26.4 & & & & & & \\
\hline Trendy & -22.6 & 15.9 & & & & & \\
\hline Low quality & 17.4 & & & & & & \\
\hline Requiring education to appreciate & & -11.4 & & & & & \\
\hline Good for health & & 14.8 & & 18.9 & & -11.1 & \\
\hline Traditional & 40.9 & & & -10.3 & & & \\
\hline Luxurious & 13.3 & & & & & & \\
\hline Innovative & -19.5 & -19.1 & 12.1 & & & & 27.4 \\
\hline Genuine taste & 16.2 & & & & & & -10.9 \\
\hline More expensive & -26.1 & 10.4 & 11.4 & & & & \\
\hline Good value for money & 41.7 & & -12.7 & & & & \\
\hline Supports local production & & & -11.8 & -17.7 & 18.1 & 25.6 & \\
\hline Linked to its origin & & & & -11.7 & & 12.9 & \\
\hline Respect for ethical values & -21.7 & & & -16.0 & 18.4 & 28.1 & \\
\hline Distinctive taste & & & & 23.9 & & & \\
\hline
\end{tabular}

Note: Table reports only deviations $\geq 10 \%$. Products: $1=$ conventional wine; $2=$ organic wine; $3=$ biodynamic wine; $4=$ wine with no added sulphites; $5=$ natural or sustainable-development wine promoted by producers' organisations; 6 = fair-trade wine; 7 = carbon-neutral wine. 
Table 7. Deviations from the expected levels of responses in the Italian sample (\%).

\begin{tabular}{|c|c|c|c|c|c|c|c|}
\hline & & & & Wine & & & \\
\hline Attribute & 1 & 2 & 3 & 4 & 5 & 6 & \#7 \\
\hline More responsible winemaker & -25.7 & & & & & & 12.6 \\
\hline Harmless to the environment & -23.0 & 14.5 & & -16.8 & & & 38.3 \\
\hline Does not cause headaches & & & & 45.2 & & & -12.9 \\
\hline Pleasurable and fun & 15.8 & & & & & & \\
\hline Trendy & & 17.5 & & & & & \\
\hline Low quality & 32.1 & -11.9 & & & & & \\
\hline Requiring education to appreciate & & & 19.1 & & & & \\
\hline Good for health & -17.8 & 16.6 & & 26.4 & & -11.1 & \\
\hline Traditional & 52.6 & -10.3 & -12.9 & & & & -10.2 \\
\hline Luxurious & & & 11.5 & & & & \\
\hline Innovative & -17.1 & & 27.9 & & & -11.7 & 14.6 \\
\hline Genuine taste & & 10.4 & & & & & -10.3 \\
\hline More expensive & -12.3 & 13.7 & 18.3 & & & & \\
\hline Good value for money & 27.0 & & -13.5 & & & & \\
\hline Support local production & & -17.3 & -11.8 & -17.8 & 21.0 & 22.5 & \\
\hline Linked to its origin & & & -10.9 & -12.6 & & & \\
\hline $\begin{array}{l}\text { Respect for ethical values } \\
\text { Distinctive taste }\end{array}$ & -25.6 & & -11.4 & -10.7 & & 33.1 & 10.6 \\
\hline
\end{tabular}

Note: Table reports only deviations $\geq 10 \%$. Products: $1=$ conventional wine; $2=$ organic wine; $3=$ biodynamic wine; $4=$ wine with no added sulphites; $5=$ natural or sustainable-development wine promoted by producers organisations; 6 = fair-trade wine; 7 = carbon-neutral wine.

Wine with no added sulphites was clearly associated with health benefits ('does not cause headaches' and 'good for health') and for French respondents, it also has a distinctive taste. Negative associations were found for its benefits to society and the environment ('harmless to the environment', 'supports local production', 'linked to its origin', and 'respect for ethical values').

Respondents expressed only positive associations with natural or sustainable-development wine promoted by producers' organisations in relation to respect for ethical values. French respondents highlighted the benefits of local production and greater responsibility of the winemaker.

Fair-trade wine was linked to its ability to support local production and respect of ethical values, but was negatively associated with harmlessness to the environment, innovativeness and healthiness.

Conversely, carbon-neutral wine was perceived as harmless to the environment and innovative. Italian respondents added the characteristics of greater responsibility of the winemaker and respect for ethical values. Carbon-neutral wine was not perceived as a traditional product with a genuine taste.

\subsection{Wine Involvement, Propensity towards EMCB, and Perceptions of Sustainable Wines}

French and Italian respondents were assigned to four clusters of consumers combining 'low' and 'high' levels of EMCB and 'low' and 'high' levels of involvement with wine. Four perceptual maps were generated to analyse the influences of $\mathrm{EMCB}$ and wine involvement on consumers' perceptions of sustainable wine (Figures 3-6). The four types of consumers are as follows: (1) low EMCB and low wine involvement (T1, Figure 3); (2) low EMCB and high wine involvement (T2, Figure 4); (3) high EMCB and low wine involvement (T3, Figure 5); and (4) high EMCB and high wine involvement (T4, Figure 6).

Two perceptions were shared by all clusters: (1) conventional wine is different from sustainable wines and is associated with tradition, good value for money and low quality; and (2) wine with no added sulphites is associated with health benefits.

The associations identified by the four clusters of respondents followed similar patterns for the other types of surveyed wine. However, some differences between clusters appeared. Less-involved consumers belonging to $\mathrm{T} 1$ and $\mathrm{T} 3$ associated specific attributes to conventional wine and wine with no added sulphites, but showed less discriminatory ability in relation to the other sustainable wines. Some products and attributes were located near the perceptual space origin (Figures 3 and 5). When involvement with wine and EMCB were low (T1), few specific attributes were clearly ascribed to sustainable wines (e.g., fair-trade wine supports local producers and respect 
for ethical values). When involvement was low but EMCB was high (i.e., among T3 consumers), natural/sustainable-development, fair-trade and carbon-neutral wines were positioned very closely to each other in the perceptual space and only an ethical value (attribute \#15 'supports local producers') received more attention than the other attributes attached to sustainable wines.

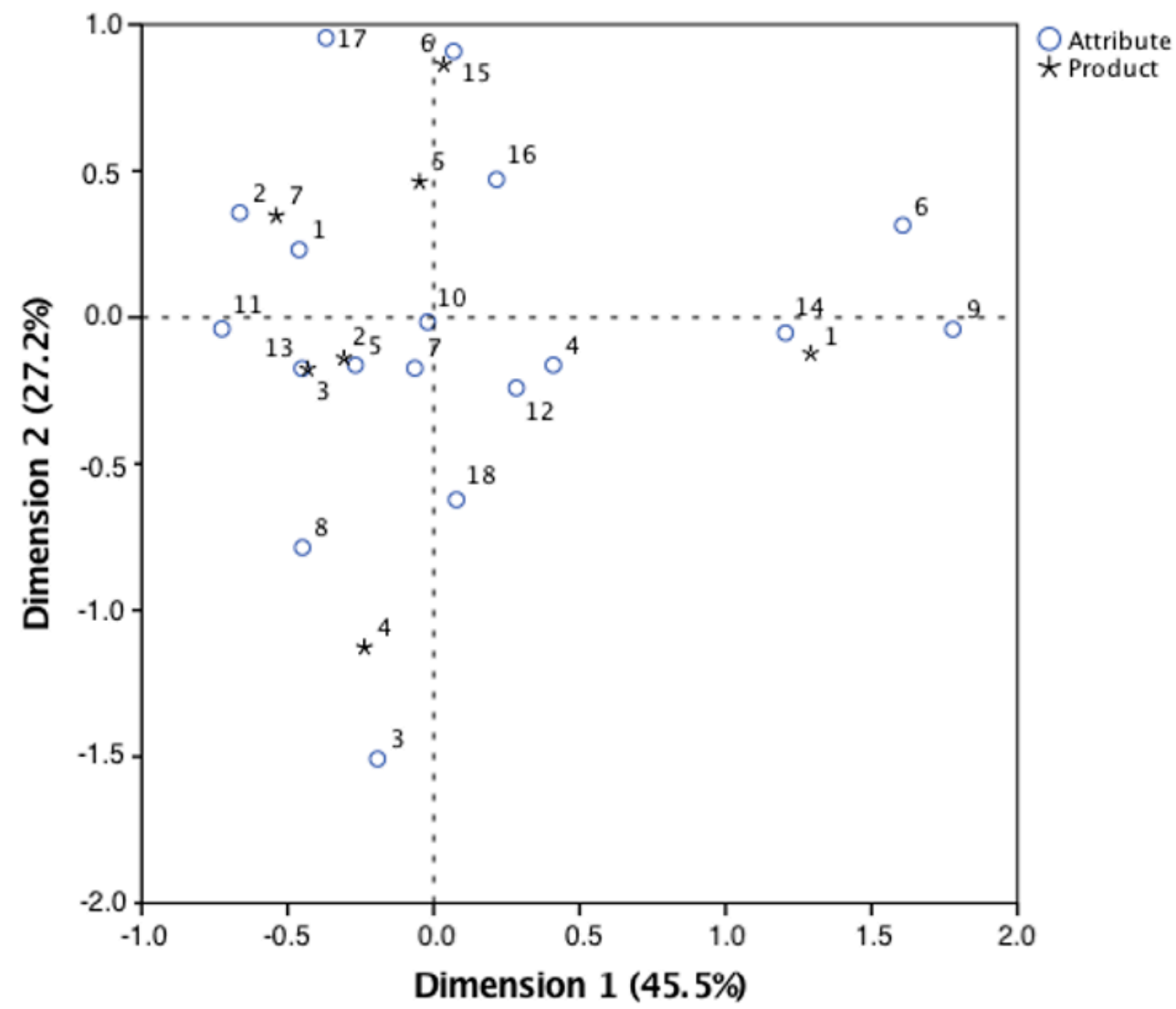

Figure 3. Perceptual map of T1 consumers (low wine involvement and low EMCB) $(N=94)$.

Consumers with high involvement with wine (i.e., T2 and T4 consumers) found it easier to ascribe product-attribute associations (e.g., the distinctive taste of wine with no added sulphites) to sustainable wines than did the other two clusters. Consumers belonging to T2, who have high involvement with wine but have low environmental and ethical consciousness, seemed to have a more developed discriminant ability for attributes than for products (Figure 4). They ascribed benefits to society such as support for local producers (fair-trade wine), respect for ethical values (natural/sustainable-development wine), more responsible winemakers, as well as harmless to the environment (carbon-neutral wine). Organic and biodynamic wines had a similar, and less distinctive, position near the origin of the perceptual map. Consumers in T4 with both high EMCB and product involvement seemed to make clearer distinctions than the other groups (Figure 6). Organic and biodynamic wines were associated with certain product characteristics and benefits (i.e., being trendy, more expensive and requiring education), while natural/sustainable-development, fair-trade and carbon-neutral wines were mainly associated with benefits to society (i.e., support for local producers and respect for ethical values).

These findings highlight that involvement with the product can influence the ability to discriminate among different types of sustainable wine for the consumer. Conversely, consumers' EMCB does not emerge as having the strength to explain differences in consumer perceptions.

Rather than consciousness of ethically minded behaviour, wine involvement seems to be the driver of consumers' perception of wine through it generating interest in and knowledge about different types of wine. 


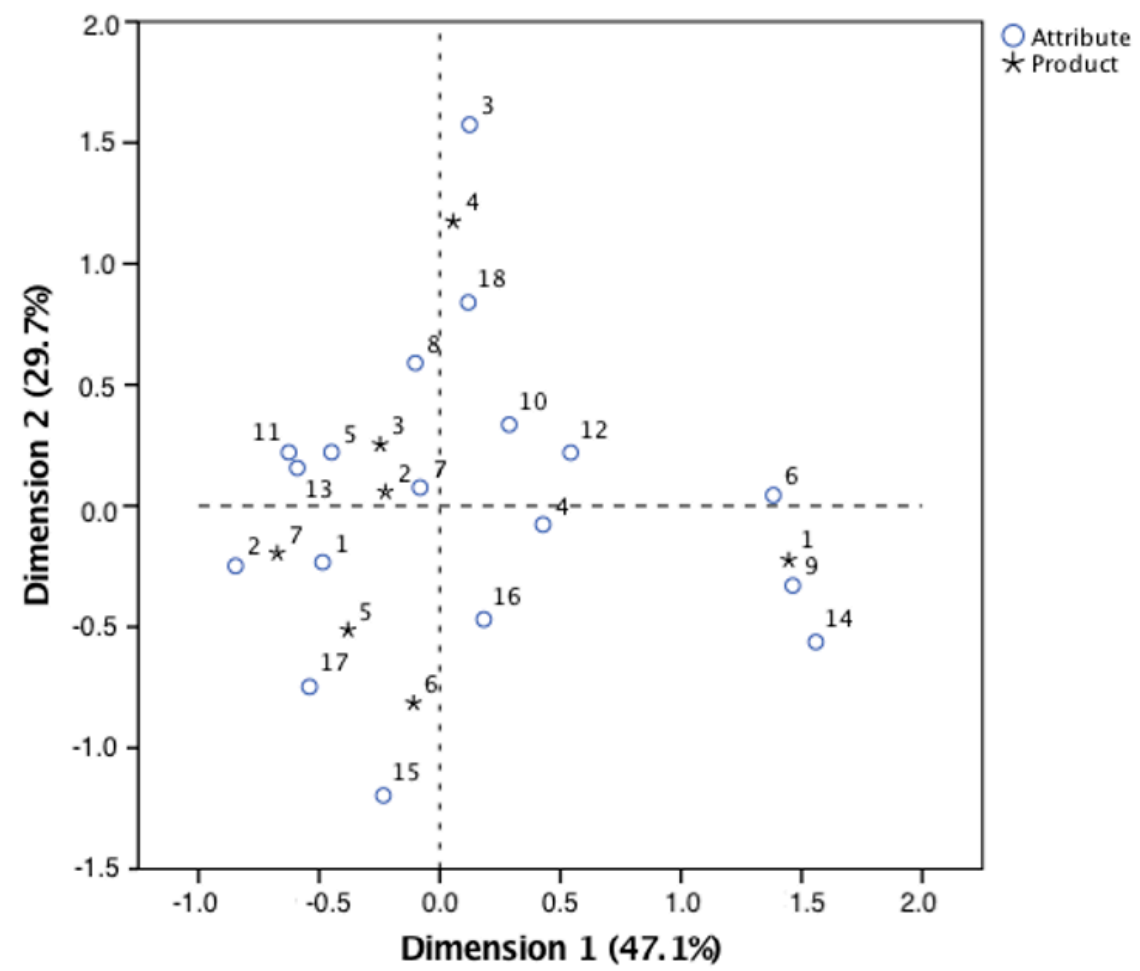

Figure 4. Perceptual map of T2 consumers (high wine involvement and low EMCB) $(N=60)$.

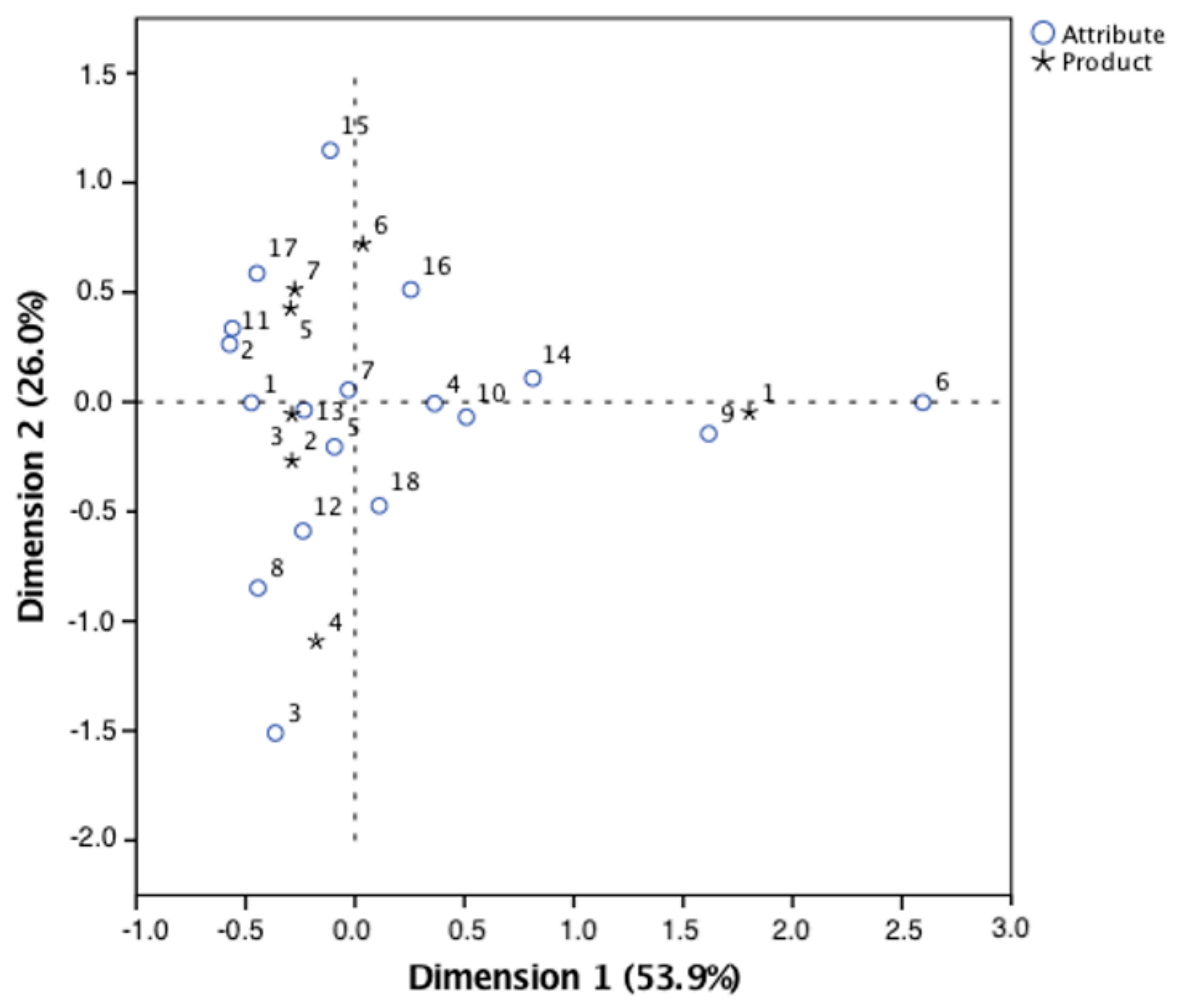

Figure 5. Perceptual map of $\mathrm{T} 3$ consumers (low wine involvement and high EMCB) $(N=66)$. 


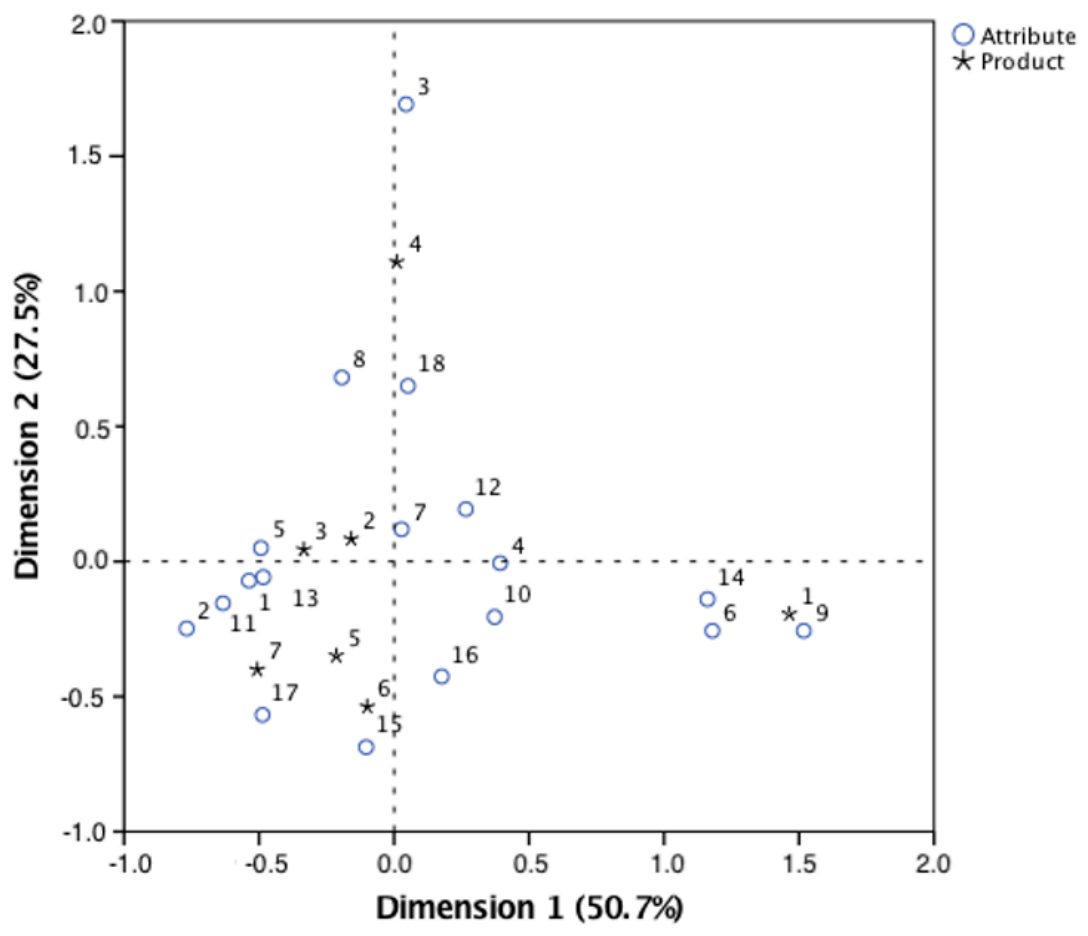

Figure 6. Perceptual map of T4 consumers (high wine involvement and high EMCB) $(N=108)$.

\section{Discussion}

In the perceptual space, French and Italian respondents clearly differentiated between conventional wine and sustainable wine, perceiving sustainable wine as innovative and trendy. This result supports Thøgersen (2017) findings in relation to food products.

Among sustainable wines, the perceptual dimension ranged from health and sensory benefits to ethical values. Wine with no added sulphites was perceived differently from the other types of sustainable wines. Organic and biodynamic wines received moderate attribute associations and were mainly associated with concrete or image characteristics. Conversely, consumers generally associated ethical attributes with natural/sustainable development, fair-trade, and carbon-neutral wines.

In combination with the market segmentations proposed by several previous studies (Pomarici and Vecchio 2014; Sogari et al. 2015; Thøgersen 2017), these results could be used to support wineries' decision-making processes in relation to product mixes and consumer targets. The perceptual space analysis demonstrates the relative distance between different types of sustainable wine. Further, the product-attribute associations identified by this study could provide a starting point for consistency in marketing combinations between product portfolio, target-market expectations (in relation to quality and sustainability) and communication campaigns.

For the French sample, the results of this study were compared with those obtained by Remaud and Sirieix (2010) in their article on perceptions of organic, biodynamic and no-added-sulphites wine. This comparison revealed that the image of conventional wine has not changed significantly in France since 2009, and that the image of organic wine remains the same for most attributes (i.e., harmless to the environment, trendy, good for health, and more expensive). However, some associations were weaker in the present study than found in previous research (Remaud and Sirieix 2010). Interestingly, the attribute 'good value for money' was negatively associated with organic wine in 2010, but was not significantly associated with organic wine in the present study. This result is consistent with the evolution of the organic-wine market in France. The important development of this market in recent years has been accompanied by a reduction in organic-wine prices. Additionally, biodynamic wine in 2010 (Remaud and Sirieix 2010) was perceived as being expensive, but in the present study was more strongly associated with being harmless to the environment, trendy, and innovative. The attribute of 
requiring education to appreciate the wine is no longer significantly associated with this type of wine. Finally, in Remaud and Sirieix (2010) and the present study, wine with no added sulphites is associated with health-related attributes.

Thus, it can be concluded that the positioning of, and familiarity with, organic and biodynamic wines has changed: both are now seen as familiar and as less expensive than they were previously. This is also consistent with the growing market share of these wines, and the decreasing price gap between them and conventional wines. The positioning of wine without sulphites has not changed.

For the Italian sample, the results confirm previous studies on the Italian sustainable-wine market (Mariani and Vastola 2015). Among the product-attribute associations, Italian respondents attach importance to respect for the environment and ethics, and the price of the products does not appear to be important to these consumers. This confirms Sogari et al. (2015) finding of a direct relationship between positive attitudes towards sustainable wine, stronger belief in environmental protection and willingness to pay more.

This study also brings new insights in relation to consumers' involvement with wine and EMCB. EMCB does not appear to be sufficient to explain differences in consumers' perceptions of different sustainable wines. Consumers who best differentiate between wines are concerned by sustainability, but above all, are involved with wine.

These results have practical relevance for wine marketers. If the positive effects of sustainable-production practices were emphasised (e.g., in terms of resource savings, waste reduction or economic and social balances), it would provide consumers involved with wine products with concrete evidence of the expected benefits of sustainable wine. For these consumers, trust-which is undoubtedly a weak point for sustainable products (Ginon et al. 2014)_could increase and the attitude-behaviour gap could decrease.

\section{Conclusions}

The present study adds to the literature by analysing in combination how wine involvement and a propensity towards ecologically and ethically-minded behaviours affect consumers' perceptions. The findings highlight that consumers' involvement with products plays a key role in determining their ability to discriminate among types of sustainable wine. Conversely, consumers' EMCB appears to influence consumers' perceptions to a lesser extent. These results are also consistent with those of Sogari et al. (2016), who demonstrated that valuing environmental protection is not significantly related to the level of importance attributed to sustainable aspects of wine. Additionally, the results are partially in line with those of Pomarici and Vecchio (2014), who identified the relevance of wine involvement but also considered other factors, such as wine-purchasing frequency and interest in sustainable foods, to reduce the attitude-behaviour gap.

This study seems to be the first to apply the EMCB scale in relation with the perceptions of wine consumers. However, the research has limitations. The first is the nature and small size of the samples, which limit the external validity of the results. Second, the study investigated only two countries of the so-called 'old world' of wine. Thanks to recent studies that have found that national cultural values and food-related lifestyles influence sustainable consumption, future studies should be conducted following a similar approach in the 'new-world' wine-producing countries or countries characterised by an emerging wine demand. Finally, this study focused on perceptions of, not on preferences for, different wines or choice of different wines. Future studies could integrate an analysis of perceptions, stated preferences and actual choices.

Indeed, the attitude-behaviour gap is an area that has not been investigated in relation to different types of sustainable wine. Scholars and marketers should pay close attention to this issue to identify the most suitable marketing and communication initiatives in relation to the type of sustainable wines they are promoting. 
Author Contributions: Conceptualization, R.C. and L.S.; Investigation, R.C. and L.S.; Methodology, R.C. and L.S.; Writing—original draft, R.C. and L.S.; Writing—review \& editing, R.C. and L.S.

Funding: This research received no external funding.

Acknowledgments: The authors are thankful to Martin Sayas and Carlotta Grimani for their assistance during questionnaire translations and the data collection in France and in Italy.

Conflicts of Interest: The authors declare no conflict of interest.

\section{References}

Adams, Richard, Sally Jeanrenaud, John Bessant, David Denyer, and Patrick Overy. 2016. Sustainability-oriented Innovation: A Systematic Review. International Journal of Management Reviews 18: 180-205. [CrossRef]

Aertsens, Joris, Wim Verbeke, Koen Mondelaers, and Guido Van Huylenbroeck. 2009. Personal determinants of organic food consumption: A review. British Food Journal 111: 1140-67. [CrossRef]

Baird, Tim, C. Michael Hall, and Pavel Castka. 2018. New Zealand Winegrowers Attitudes and Behaviours towards Wine Tourism and Sustainable Winegrowing. Sustainability 10: 797. [CrossRef]

Barber, Nelson, Barbara Almanza, and Tim Dodd. 2008. Relationship of wine consumers' self-confidence, product involvement, and packaging cues. Journal of Foodservice Business Research 11: 45-64. [CrossRef]

Bruwer, Johan, and Jieshan Huang. 2012. Wine product involvement and consumers' BYOB behaviour in the South Australian on-premise market. Asia Pacific Journal of Marketing and Logistics 24: 461-81. [CrossRef]

Carrington, Michal J., Benjamin A. Neville, and Gregory J. Whitwell. 2014. Lost in translation: Exploring the ethical consumer intention-behavior gap. Journal of Business Research 67: 2759-67. [CrossRef]

Casini, Leonardo, Armando Maria Corsi, and Steve Goodman. 2009. Consumer preferences of wine in Italy applying best-worst scaling. International Journal of Wine Business Research 21: 64-78. [CrossRef]

CBI. 2016. CBI Product Factsheet: Sustainable wine in Europe. In CBI Market Intelligence; The Hague: Ministry of Foreign Affairs.

De Salvo, Maria, Roberta Capitello, and Diego Begalli. 2018. How CS can be used for gaining info about consumers and the market? In Case Studies in the Wine Industry, 1st ed. Edited by Cristina Santini and Alessio Cavicchi. Sawston: Woodhead Publishing, ISBN 9780081009444.

Dowd, Kylie, and Karena J. Burke. 2013. The influence of ethical values and food choice motivations on intentions to purchase sustainably sourced foods. Appetite 69: 137-44. [CrossRef] [PubMed]

Driesener, Carl, and Jenni Romaniuk. 2006. Comparing methods of brand image measurement. International Journal of Market Research 48: 681-98. [CrossRef]

FAO. 2018. Transforming Food and Agriculture to Achieve the SDGs. Roma: FAO, ISBN 9789251306260. Available online: http://www.fao.org/3/I9900EN/i9900en.pdf (accessed on 28 October 2018).

Flores, Shana Sabbado. 2018. What is sustainability in the wine world? A cross-country analysis of wine sustainability frameworks. Journal of Cleaner Production 172: 2301-12. [CrossRef]

Gilinsky, Armand, Jr., Sandra K. Newton, and Rosana Fuentes Vega. 2016. Sustainability in the global wine industry: Concepts and cases. Agriculture and Agricultural Science Procedia 8: 37-49. [CrossRef]

Ginon, Emilie, Gastòn Ares, Lùcia H. E. dos Santos Laboissière, Joëlle Brouard, Sylvie Issanchou, and Rosires Deliza. 2014. Logos indicating environmental sustainability in wine production: An exploratory study on how do Burgundy wine consumers perceive them. Food Research International 62: 837-45. [CrossRef]

Grunert, Klaus G., Sophie Hieke, and Josephine Wills. 2014. Sustainability labels on food products: Consumer motivation, understanding and use. Food Policy 44: 177-89. [CrossRef]

Klöckner, Christian A. 2013. A comprehensive model of the psychology of environmental behaviour-A meta-analysis. Global Environmental Change 23: 1028-38. [CrossRef]

Lockshin, Larry, and Tony Spawton. 2001. Using involvement and brand equity to develop a wine tourism strategy. International Journal of Wine Marketing 13: 72-81. [CrossRef]

LSA. 2018. Quels Sont les dix Premiers Marchés Mondiaux du vin bio? Sylvie Leboulenger. LSA. Available online: https://www.lsa-conso.fr/quels-sont-les-dix-premiers-marches-mondiaux-du-vin-bio,304451 (accessed on 3 December 2018).

Mann, Stefan, Ali Ferjani, and Linda Reissig. 2012. What matters to consumers of organic wine? British Food Journal 114: 272-84. [CrossRef] 
Mariani, Angela, and Antonella Vastola. 2015. Sustainable winegrowing: Current perspectives. International Journal of Wine Research 7: 37-48. [CrossRef]

Martins, António A., Ana R. Araújo, António Graça, Nídia S. Caetano, and Teresa M. Mata. 2018. Towards sustainable wine: Comparison of two Portuguese wines. Journal of Cleaner Production 183: 662-76. [CrossRef]

Minton, Elizabeth A., Nathalie Spielmann, Lynn R. Kahle, and Chung-Hyun Kim. 2018. The subjective norms of sustainable consumption: A cross-cultural exploration. Journal of Business Research 82: 400-8. [CrossRef]

Moscovici, Daniel, and Alastair Reed. 2018. Comparing wine sustainability certifications around the world: History, status and opportunity. Journal of Wine Research 29: 1-25. [CrossRef]

Mueller Loose, Simone, and Hervé Remaud. 2013. Impact of corporate social responsibility claims on consumer food choice: A cross-cultural comparison. British Food Journal 115: 142-66. [CrossRef]

Pomarici, Eugenio, and Riccardo Vecchio. 2014. Millennial generation attitudes to sustainable wine: An exploratory study on Italian consumers. Journal of Cleaner Production 66: 537-45. [CrossRef]

Reisch, Lucia A., Ulrike Eberle, and Sylvia Lorek. 2013. Sustainable food consumption: An overview of contemporary issues and policies. Sustainability: Science, Practice, $\mathcal{E}$ Policy 9: 1-19. [CrossRef]

Remaud, Hervé, and Lucie Sirieix. 2010. Consumer perceptions of eco-friendly vs. conventional wines in Australia. Paper presented at 5th International Academy of Wine Business Research Conference, Auckland, New Zealand, February 8-10.

Remaud, Hervé, and Lucie Sirieix. 2012. Les vins éco-labellisés face aux vins conventionnels en France et en Australie: Quelle perception des consommateurs et quelles implications marketing? Décisions Marketing 67: 23-35. [CrossRef]

Rojas-Méndez, José I., Manon Le Nestour, and Michel Rod. 2015. Understanding attitude and behavior of Canadian consumers toward organic wine. Journal of Food Products Marketing 21: 375-96. [CrossRef]

Santini, Cristina, Alessio Cavicchi, and Leonardo Casini. 2013. Sustainability in the wine industry: Key questions and research trends. Agricultural and Food Economics 1: 9. [CrossRef]

Schäufele, Isabel, and Ulrich Hamm. 2017. Consumers' perceptions, preferences and willingness-to-pay for wine with sustainability characteristics: A review. Journal of Cleaner Production 147: 379-94. [CrossRef]

Schäufele, Isabel, and Ulrich Hamm. 2018. Organic wine purchase behaviour in Germany: Exploring the attitude-behaviour-gap with data from a household panel. Food Quality and Preference 63: 1-11. [CrossRef]

Shine. 2018. Organic Wine Market Grows Fast but Is Set to Remain Niche. ShanghaiDaily.com. Available online: https://archive.shine.cn/feature/ideal/Organic-wine-market-grows-fast-but-is-set-to-remain-niche/ shdaily.shtml (accessed on 3 December 2018).

Sinab. 2018. Il bio in cifre 2018, Anticipazioni. Ismea, Mipaaf, Ciheam. Roma. Available online: http: //www.sinab.it/sites/default/files/share/Bio\%20in\%20cifre\%202018\%20_\%20Anticipazioni_1.pdf (accessed on 16 December 2018).

Sirieix, Lucie, Marion Delanchy, Hervé Remaud, Lydia Zepeda, and Patricia Gurviez. 2013. Consumers' perceptions of individual and combined sustainable food labels: A UK pilot investigation. International Journal of Consumer Studies 37: 143-51. [CrossRef]

Sogari, Giovanni, Chiara Corbo, Martina Macconi, Davide Menozzi, and Cristina Mora. 2015. Consumer attitude towards sustainable-labelled wine: An exploratory approach. International Journal of Wine Business Research 27: 312-28. [CrossRef]

Sogari, Giovanni, Cristina Mora, and Davide Menozzi. 2016. Factors driving sustainable choice: The case of wine. British Food Journal 118: 632-46. [CrossRef]

Spielmann, Nathalie. 2017. Larger and better. Examining how winery size and foreign investments interact with sustainability attitudes and practices. International Journal of Wine Business Research 29: 178-94. [CrossRef]

Sudbury-Riley, Lynn, and Florian Kohlbacher. 2016. Ethically minded consumer behavior: Scale review, development, and validation. Journal of Business Research 69: 2697-710. [CrossRef]

Szolnoki, Gergely. 2013. A cross-national comparison of sustainability in the wine industry. Journal of Cleaner Production 53: 243-51. [CrossRef]

Thøgersen, John. 2011. Green shopping: For selfish reasons or the common good? American Behavioral Scientist 55: 1052-76. [CrossRef]

Thøgersen, John. 2017. Sustainable food consumption in the nexus between national context and private lifestyle: A multi-level study. Food Quality and Preference 55: 16-25. [CrossRef] 
UN. 2015. Transforming Our World: The 2030 Agenda for Sustainable Development. A/Res/70/1. United Nations. Available online: https:/sustainabledevelopment.un.org/content/documents/21252030\%20Agenda\%20for\% 20Sustainable\%20Development\%20web.pdf (accessed on 21 October 2018).

Vermeir, Iris, and Wim Verbeke. 2006. Sustainable food consumption: Exploring the consumer “attitude-behavioral intention" gap. Journal of Agricultural and Environmental Ethics 19: 169-94. [CrossRef]

Yuan, Jingxue, Alastair M. Morrison, Liping A. Cai, Tim H. Dodd, and Sally Linton. 2008. Segmenting wine festival visitors using their personal involvement with wine. In Food and Wine Festivals and Events around the World: Development, Management and Markets. Edited by C. Michael Hall and Liz Sharples. Abingdon-on-Thames: Routledge.

(C) 2019 by the authors. Licensee MDPI, Basel, Switzerland. This article is an open access article distributed under the terms and conditions of the Creative Commons Attribution (CC BY) license (http://creativecommons.org/licenses/by/4.0/). 